\title{
RUSSISCHE GRAMMATIK
}

von

\author{
DR. ER I C H B ER N E K ER \\ ord. Professor an der Universitut Monchen \\ Sechste, verbesserte Auflage \\ von
}

DR. MAX VASMER

emer. ord. Professor an der Freien Universităt Berlin

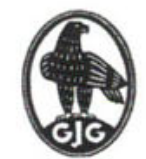

\section{WALTER DE GRUYTER \& CO.}

vormals G. J. Göschen'sche Verlagshandlung - J. Gutteotag,

Verlagabuchhandlung - Georg Reimer - Karl J. Trübner - Veit \& Comp.

B E R L I N 1961 
Alle Rechte, insbesondere das Obersetzungsrecht, von der Verlagshandung vorbehalten

Copyright 1961 by Walter de Gruyter \& Co., Berlin W 30 - Alle Rechte, einschl. der Rechte der Herstelluing von Photokopien und Mikrofilmen, von der V'erlagshandlung vorbehalten. - Archiv-Nr. 110066.

Druck: Thormann \& Goetsch, Berlin-Neukölln. - Printed in Germany 